\title{
BANQUETES, MANJARES DESUSADOS
}

\author{
Luis Maffei \\ (Universidade Federal Fluminense)
}

\section{RESUMO}

O Canto VI d'Os Lusíadas apresenta algumas das questões centrais do poema. Uma delas diz respeito a uma série de desdobramentos que se anunciam nesse ponto da narrativa, a partir de dicotomias que opõem, aparentemente, gozo alimentar x valor sacrificial, por exemplo, para explodir em lugares futuros. Os manjares e os banquetes são lugares de partida, e também de chegada, de muito dessa discussão, que envolve Veloso, Vênus, Baco, vinho, amor, etc.

PALAVRAS-CHAVE: Os Lusíadas, comida e vinho, prazer e amor.

\begin{abstract}
Os Lusíadas in its Chant VI presents some of the central issues of the poem. One of them relates to a series of developments that advertise themselves, in that point on the narrative to explode in future moments, from dichotomies that oppose, apparently, pleasure with food vs. sacrificial value, for instance. The delicacies and banquets are points of departure and arrival for much of this discussion, that envolves Veloso, Venus, Bacchus, wine, love and so on.
\end{abstract}

KEYWORDS: Os Lusíadas, food and wine, pleasure and love. 
A etimologia da palavra manjar nos leva ao francês do século $\mathrm{X}$, nomeadamente ao famoso verbo manger, tão atual, na língua de Verlaine, quanto o ato por ele expresso. Ao fundo, como está dito, por exemplo, pelo italiano mangiare, está o latim manducare, mastigar, pois comer, como nos ensinam línguas anglo-saxãs, se dizia edere em Roma e adjacências. A excepcional aba etimológica do Dicionário eletrônico Houaiss da Língua Portuguesa 1.0 indica que manjar veio do francês do século $\mathrm{X}$ pois foi essa língua, nesse momento, que substantivou o verbo. Foi dela, portanto, que tomamos substantivo comum de tão rara noção.

Há oito ocorrências de "manjar" ou "manjares" n’Os Lusíadas mais precisamente, quatro no singular e quatro no plural. A expressão que tomei emprestada para título deste texto, "manjares desusados" (VI, 2, 7) aparece no Canto VI, quando Vasco da Gama se despede do Rei de Melinde, que agasalho tão fecundo lhe tinha dado, rumo a Calecute, aonde chegará ainda nesse Canto. A aparição seguinte se dá também no VI, bem próxima a seu final. Por agora, temos isso: "manjares desusados" na segunda estância do Canto VI, "manjares novos e esquisitos" (VI, 96, 1) na 96, fim da sexta parte do poema na 99.

$\mathrm{O}$ antecedente imediato do Canto VI é a descompostura que Camões dá em Vasco da Gama no final do V, logo após o Capitão desabonar "toda grandíloqua escritura" (V, 89, 8). Na diegese, a história de Portugal já fora contada pela boca do irmão mais poderoso de Paulo, e os portugueses têm de deixar Melinde, com piloto e tudo, rumo à "desejada parte Oriental" $(\mathrm{V}, 69,8)$. A íntegra das estâncias de abertura do Canto VI é:

Não sabia em que modo festejasse

O Rei Pagão os fortes navegantes,

Pera que as amizades alcançasse

Do Rei Cristão, das gentes tão possantes;

Pesa-lhe que tão longe o apousentasse

Das Europeias terras abundantes

A ventura, que não no fez vizinho

Donde Hércules ao mar abriu caminho.

Com jogos, danças e outras alegrias,

A segundo a polícia Melindana,

Com usadas e ledas pescarias,

Com que a Lageia António alegra e engana

Este famoso Rei, todos os dias,

Festeja a companhia Lusitana,

Com banquetes, manjares desusados,

Com frutas, aves, carnes e pescados. (VI, 1, 2)

A rima do dístico final da primeira estrofe é em -inho: "vizinho", "caminho"; depois digo por que isso me chama a atenção. Antes, fico em alguns adjetivos de conotação positiva: "fortes" e "possantes" são os por- 
tugueses, "abundantes" as terras de Portugal e "ledas" as "pescarias"; os "manjares", como já sabemos, "desusados". E nalguns verbos: festejar é o primeiro da estrofe, portanto do Canto. A festa começa logo após um pito do próprio poeta contra o Gama, e a reprimenda, evidentemente, não é, no plano histórico, ouvida pelo comandante da esquadra: sintoma, entre tantos, da surdez que bloqueia o canto a variados receptores. De qualquer maneira, o que diz Camões ao militar, fala prenhe de valor, não se encontra dentro da dimensão épica da viagem, mas num texto cujo emissor não é adequado aos princípios canônicos do gênero por vezes posto em cena n'Os Lusíadas, pois quem fala ali é o próprio poeta, que, aliás, sobejamente silencia as vozes narrativas que engendra a fim de criar outras zonas de significação no poema.

Depois da bronca, a festa dada pelos melindanos para adiar a despedida. O encontro, no Canto II, também foi saudado por uma grande festividade, antecessora do longo relato do Gama. No VI, a "polícia", ou seja, os hábitos locais, manda haver "banquetes, manjares desusados/ Com frutas, aves, carnes e pescados". É lamentável para os africanos, diz a estância 1, estarem tão distantes de Portugal, longe de onde "Hércules ao mar abriu o caminho", ou seja, onde África é próxima da Ibéria. As festas e "pescarias" que os portugueses recebem são comparadas pelo narrador épico às que Cleópatra pratica e com as quais "alegra e engana” António, ou o contrário, dada a ambiguidade do verso, que pode ter, como sujeito dos verbos alegrar e enganar, "Lageia" ou "Antônio". Isso porque, diz a história, Marco Antônio era muito inábil na arte da pescaria, e, certa vez, tentou enganar Cleópatra, ordenando que um escravo capturasse um peixe como se fosse obra do militar. $\mathrm{O}$ nada amargo revide da divina personagem, que percebeu o truque do amante, é assim descrito por Stacy Schiff:

Um grande grupo acorre no dia seguinte. Já de início, Cleópatra dá algumas ordens furtivas. Antônio lança a linha, com resultado imediato. Ele sente um grande peso e puxa a presa, diante de uma onda de risadas: do Nilo retira um arenque salgado, importado do mar Negro. Cleópatra aproveita a artimanha para mostrar a superioridade de sua inteligência - Antônio não era o único a se sentir obrigado a impressionar -, mas também para lembrar seu amante, com habilidade, firmeza e doçura, de suas responsabilidades maiores. (SCHIFF, 2011, p. 190)

O engano, no episódio referido por Camões, é de dupla face Antônio enganou Cleópatra e ela lhe deu o troco, enganando-o depois. A palavra engano, na lírica de Camões em geral e n’Os Lusíadas em particular, poderia ser tema de muitas páginas e controvérsias, mas me basta assinalar que é vocábulo associado a Baco, especialmente em estratégica sequência do Canto I. Na estância 73, o deus, diz o narrador, "No pensamento cuida um falso engano" (I, 73, 5); já na 76 , o próprio Baco toma a palavra e diz, em solilóquio: "[...] antes que chegado/ Seja este Capitão, astutamente/ Lhe será tanto engano fabricado/ Que nunca veja as partes do Oriente” (I, 76, 
1-4). Na 79, enfim, a palavra é, pelo Tioneu, associada aos portugueses, pois, antropomorfizado em moçambicano sábio, ele diz a crédulo mouro, entre outras coisas, que os viajantes "trazem já de longe engano urdido/ Contra nós; e que todos seus intentos/ São para nos matarem e roubarem,/ E mulheres e filhos cativarem." (I, 79, 5-8).

O engano, num intervalo de menos de dez estâncias, aparece em duas vozes, a do narrador e a de Baco, colado a antagonistas, os portugueses em viagem e o deus que gostaria de sabotá-la. No Canto VI, a associação de engano à tentativa melindana de manter ali os portugueses sabe a um gesto de sedução, mais próximo ao engano feito por Antônio a Cleópatra que ao feito, segundo Schiff, com intenções pedagógicas, por Cleópatra a Antônio. Essa sedução ao menos toca um dos sentidos mais profundos da ideia de engano em Camões, que é o amoroso, "engano da alma, ledo e cedo" (III, 120, 3), como se lê por causa de Inês de Castro, e eu contemplo aqui um amor associado ao prazer, amor terreno - por isso, o sintagma "alegra e engana" não me soa, estando em Camões, estranho. A sedução dos africanos aos portugueses pode ser considerada próxima a um sentido estético, tanto nos fogos que explodem ao fim do Canto III como nos sabores sem fim do começo do VI. Penso que uma das razões por que os melindanos passaram a apreciar tanto os portugueses foi o relato do Gama, inclusive no que ele tem de sabor narrativo, literário. A propósito, há uma estética forte no encontro ocorrido em Melinde desde as vestes do Capitão e do Rei que representam suas respectivas gentes.

Mas há mais que isso, há também poder. Nesse caso, os "banquetes, manjares desusados" servidos aos portugueses não apenas acariciam seus paladares e os deslocam a território cheio de gozo. Assim começa o Canto VI: "Não sabia em que modo festejasse/ O Rei Pagão os fortes portugueses,/ Pera que as amizades alcançasse/ Do Rei Cristão, das gentes tão possantes". Sim, manjares para agradar e para alcançar uma amizade, sim, saborosa, sem dúvida estética mas, por que não?, também, de um ponto de vista politicamente comezinho, interesseira. Portanto, sedução mas poder, gozo mas interesse, e isso logo antes de um dos acontecimentos centrais do poema, que é o mergulho de Baco no reino netunino numa desesperada tentativa, uma das últimas, de convocar aliados para a destruição do projeto que os seus descendentes portugueses levavam a cabo. Na estância 7 , como o assunto não deixa de ser o poder, a palavra surge, claríssima: "Via estar todo o Céu determinado/ De fazer de Lisboa nova Roma:/ Não no pode estorvar, que destinado/ Está doutro Poder que tudo doma” (VI, 7, 5-8). Como quem fala é o narrador, esse "Poder", especialmente num contexto em que Roma é citada, tem a ver com fé católica, Deus, Igreja, uma das justificações da viagem e da consequente colonização.

Como a fé, no poema, é quase sempre problemática ou ambígua, não leio Roma apenas como sede de poder religioso, mas de poder imperial, e sabemos que o poder religioso não se divorcia de outros poderes; se o fizesse, correria tremendo risco de deixar de ser poder. Salto, e depois vol- 
tarei a Baco, ao final do Canto VI, mais precisamente à próxima ocorrência de manjar n’Os Lusíadas, na estância 96. É preciso citar também a anterior:

Por meio destes hórridos perigos,

Destes trabalhos graves e temores,

Alcançam os que são de fama amigos

As honras imortais e graus maiores:

Não encostados sempre nos antigos

Troncos nobres de seus antecessores;

Não nos leitos dourados, entre os finos

Animais de Moscóvia zebellinos;

Não com os manjares novos e esquisitos,

Não com os passeios moles e ociosos,

Não cos vários deleites e infinitos,

Que afeminam os peitos generosos,

Não com os nunca vencidos appetitos,

Que a Fortuna tem sempre tão mimosos,

Que não sofre a nenhum que o passo mude

Pera algũa obra heroica de virtude; (VI, 95, 96)

O que está em causa, assim que os portugueses chegam à Índia, na estrofe 92, é o trabalho e o valor do trabalho para que se obtenha a glória. Os que são dignos da fama alcançam-na enquanto afirmam seus nomes através de esforços e "perigos", pondo em causa inclusive a própria vida. Logo, os "banquetes, manjares desusados" que aparecem no começo do Canto, aprazendo a permanência dos lusos em Melinde são, agora, negados, junto ao táctil, repousante e sensual desfrute de "leitos dourados", em nome de um valor mais alto, o da glória conquistada, como se lê na estrofe seguinte, a 97:

Mas com buscar, co seu forçoso braço,

As honras que ele chame próprias suas;

Vigiando e vestindo o forjado aço,

Sofrendo tempestades e ondas cruas,

Vencendo os torpes frios no regaço

Do Sul, e regiões de abrigo nuas,

Engolindo o corruto mantimento

Temperado com um árduo sofrimento; (VI, 97)

Não é com "manjares novos e esquisitos", ou seja, com gozo, que se alça o valor do homem ambicioso e merecedor da imortalidade. Nem com "vários deleites e infinitos,/ Que afeminam os peitos generosos". Ao final, "o peito um calo honroso cria,/ Desprezador das honras e dinheiro,/ Das honras e dinheiro que a ventura/ Forjou, e não vertude justa e dura." (VI, 98, 5-8) A fala é masculina, baseada em valores militares e eleitora de uma dimensão do eterno, consequência de conquistas valorosas e guerrei- 
ras, em detrimento de algo que se situe entre o mundano e o casual - merecem atenção os versos da 96 em que aparecem o desejo e a Fortuna: "Não cos nunca vencidos appetitos,/ Que a Fortuna tem sempre tão mimosos". Mundo opõe-se a eternidade, posto que, depois do desaparecimento do herói do mundo, ficarão suas obras. Assim, "onde tiver força o regimento/ Direito e não de afeitos ocupado,/ Subirá (como deve) a ilustre mando,/ Contra vontade sua, e não rogando." (VI, 5-8). Os virtuosos, além disso, devem criar suas próprias famas, "Não encostados sempre nos antigos/ Troncos nobres de seus antecessores".

A estância 97 desmonta o valor do gozo, acentuando, talvez, o caráter de engano que há no prazer terreno, e tornando ainda mais próximas, num desabonador sentido, as ideias de engano e alegria. O começo do Canto VII é um chamado católico à verdadeira expansão religiosa, como que convocando os portugueses à coerência acerca de um dos pilares da viagem, o primeiro, a "Fé", anterior a "Império" (I, 2, 3). Laivos de crítica ao protestantismo herdeiro de Lutero, talvez rastros de uma dicção que se encontra também em "alguns sonetos cristológicos" que, segundo Vítor Aguiar e Silva, foram escritos por um Camões velho, na altura em que "o sofrimento físico e moral o atribulava" e nos quais se vê "um sentimento de culpa que se adensou sombriamente nesses derradeiros tempos" (SILVA, 2009, p. 162, 163). Sem dúvida, doze estâncias, da 2 à 13, são legibilíssimas em perspectiva, por exemplo, a "Sôbolos rios que vão". Penso que há bastante aderência, no contexto épico d'Os Lusíadas, entre os valores militar e religioso, entre o fim do VI e o começo do VII. Nesse contexto, o gosto dos manjares, "desusados" ou "esquisitos", ou seja, raros ou apreciáveis, tem que ver com o sentido mais baixo de engano.

Isso, sabemos com ou sem Inês, não é estranho ao feminino, pois engano é afim a amor, amor, a desejo, e desejo, camonianamente, a feminino. O Canto VI tem uma ação central e outra coadjuvante, mas a coadjuvante é fundamental para se entender a central, e estou pensando num conjunto que reúne amor, feminino e gozo alimentar. Se há oito ocorrências de manjar e/ou manjares no poema, há apenas duas de banquete, ambas no plural. A primeira já vimos, no começo do Canto VI; a segunda tem lugar no mesmo canto, mais para o fim, na conclusão do que chamei de relato coadjuvante, mas que fica melhor se eu chamar de ação analógica. Refiro-me ao causo que Veloso conta aos colegas navegadores a fim de matar um tempo morto na viagem.

Resumo da ópera dos Doze de Inglaterra: diante da impossibilidade de contar com patrícios para solucionar discórdia levantada "Entre as damas gentis da corte Inglesa/ E nobres cortesãos” (VI, 44, 1, 2), já que eles, tomados de um poder masculino tão torpe como os dos assassinos de Inês, as ameaçam, o Duque de Alencastro, pai da rainha de Portugal, pede ajuda a D. João I. O sogro do rei diz, entre outras coisas, isto:

E se, agravadas damas, sois servidas, Por vós the mandarei embaixadores, Que, por cartas discretas e polidas, 
De vosso agravo os façam sabedores.

Também, por vossa parte, encarecidas

Com palavras de afagos e de amores

Lhe sejam vossas lágrimas, que eu creio

Que ali tereis socorro e forte esteio. (VI, 49)

Mesmo antes do encontro em terras bretãs, já é dita, pelo duque, a palavra "amores". Após cada dama escrever a seu embaixador uma carta comovida de convocação ética, sentimental e bélica, partem os Doze do Douro, mas um deles, o Magriço, por ter decidido ir por terra, quase se atrasa, o que deixa "aquela, a quem fora em sorte dado" (VI, 59, 1), enlutada. Mas o cavaleiro chega a tempo, e os doze portugueses derrotam os doze ingleses com grande autoridade. O resultado disso é contado no fim de 66 e em 67:

$[\ldots]$

Cos nossos fica a palma da vitória

$\mathrm{E}$ as damas, vencedoras e com glória.

Recolhe o Duque os doze vencedores

Nos seus paços, com festas e alegria;

Cozinheiros ocupa e caçadores,

Das damas a fermosa companhia,

Que querem dar aos seus libertadores

Banquetes mil, cada hora e cada dia,

Enquanto se detem em Inglaterra,

Até tornar à doce e cara terra. (VI, 66, 7-8/ 67)

Aqui a segunda e última ocorrência da palavra "banquetes" no poema, ainda que não o último banquete. Etimologicamente, banquete, diz-me o Dicionário Houaiss 1.0, vem do francês banquet, festim, que, por sua vez, se origina do italiano banquetto, barco pequeno, reunião em torno de comida em que as pessoas envolvidas tomavam decisões - algo como nosso hodierno almoço de negócios. É preciso, portanto, haver bastante gente para um banquete acontecer, desde a etimologia. Os dois banquetes assim nomeados n'Os Lusíadas envolvem muitos comensais, e o último deles em circunstância, mais que festiva, amorosa. Ao contrário do final do Canto VI e do começo do VII, o cavaleiresco relato dos Doze de Inglaterra não associa força masculina a eternidade ou fé, e não celebra qualquer ideia de sacrifício. Ao contrário, o gozo experimentado ao final da campanha é justo, e justo que articule amor, festa e paladar: há cozinheiros a preparar o resultado do trabalho dos caçadores, e damas a se preparar para "dar aos seus libertadores" os banquetes que, gloriosamente, ocupam os paços do pai de Filipa de Lencastre.

Já está evidente que, n’Os Lusíadas, o gozo do paladar, terreno e humano, não é alheio a amor, gozo dos sentidos, terreno e humano. Fora disso, sacrifícios e recusa do prazer - "Não com os manjares novos e esqui- 
sitos", por exemplo, e "Não com os vários deleites e infinitos,/ Que afeminam os peitos generosos". Por que chamo eu de analogia ao causo contado por Veloso? Tenho em mente, inclusive, a já declarada questão do feminino, central para Camões, tanto na épica, como na lírica. Em primeiro lugar, porque quem a conta é Veloso, conhecido por sua força como militar - "É Veloso no braço confiado" (V, 31, 1), diz Vasco da Gama enquanto relata uma das aventuras guerreiras da viagem. Quando vai entreter os colegas, Veloso toma a palavra de Lionardo, "que trazia/ Pensamentos de firme namorado" (VI, 40, 7-8) e queria falar de amor. Seu colega diz: "Antes de guerra férvida e robusta/ A nossa história seja, pois dureza/ Nossa vida há-de ser, segundo entendo/ Que o trabalho por vir mo está dizendo." (VI, 41, 5-8).

Portanto, tudo o que citei do relato dos Doze de Inglaterra foi dito por Veloso, decidido a fala marcial. Pois bem, a estória que conta o confiado em seu próprio braço fala de braço para, passando por amores, chegar à estância 67, que celebra um convívio doce entre homens e mulheres em meio a "Banquetes mil", coisa que, dirá depois o narrador épico, afemina "os peitos generosos". Não custa dizer que Veloso, um bravo soldado, decide falar da guerra e acaba falando de amor e feminino, caindo numa das mais camonianas armadilhas, pois tudo, ou quase tudo, em Camões serve a quem vence, o vencedor, ou seja, acaba se referindo ao sentimento amoroso - ou seja, a balaustrada cavaleiresca em que o navegador se apoia a fim de falar viril não o protege de um falar feminil. Veloso está, pois, feminizado, e isso, já rematarei, faz dele uma personagem analógica a outra, e seu dito analógico a outro, dentro do Canto VI.

O que Veloso desfia se situa, na macronarrativa, entre o consílio marítimo dos deuses e a consequência da reunião oceânica. $\mathrm{O}$ centro do Canto VI é ocupado pelo mergulho de um desesperado Baco que tenta, mais uma vez sem sucesso, sabotar a viagem dos portugueses. Entre uma ocorrência e outra de "manjares", depois dos "banquetes" melindanos e antes dos bretões, o pai de Luso convoca seus colegas aquáticos para uma reunião, e seu discurso, de abandono e tristeza, centra-se numa ideia de justiça sem qualquer engano, pois há, segundo a báquica mirada, perversão no êxito da viagem, como bem se lê na estância 30:

$[\ldots]$

Vistes, e ainda vemos cada dia,

Soberbas e insolências tais, que temo

Que de Mar e do Céu, em poucos anos,

Venham Deuses a ser, e nós, humanos.

Vedes agora a fraca gèração

Que dum vassalo meu o nome toma,

Com soberbo e altivo coração

A vós e a mi e o mundo todo doma.

Vedes, o vosso mar cortando vão, 
Mais do que fez a gente alta de Roma;

Vedes, o vosso reino devassando,

Os vossos estatutos vão quebrando. (VI, 29, 5-8/ 30)

Também como justa é recebida a fala de Baco, e todos os deuses marinhos, liderados por Netuno, são pelo aniquilamento da frota comandada por Vasco da Gama. A única ocorrência importante de "engano" nos arredores da palestra indignada refere-se a Glauco, aquando da exposição da chegada das entidades mitológicas marinhas ao consílio, nomeadamente à transformação de Cila em monstro por Circe, que lançou mão de "feio engano" (VI, 24, 6) - mais uma vez engano se liga a amor, pois "a mais obriga amor mal empregado" (VI, 24, 8). Luiza Nóbrega, estudiosa que se dedica a'Os Lusíadas dando especial atenção a Baco, entende que a água é um elemento natural para o deus, não apenas por razões mitológicas, mas por uma dinâmica interna ao poema: "As águas, em forma de lágrimas, fontes, ondas, licor de Lieu, mundo submarino, são passadas de mão a mão, de trecho a trecho, de Canto a Canto, como fio de continuidade do sentimento, como voz da parte excluída [...]" (NÓBREGA, 2013, p. 544).

O fim do Canto VI propõe um sacrifício, e é sacrificial, para o sujeito enunciador do poema, a escrita da obra. Uma semelhança estrutural é apreciável: o discurso sobre sacrifício e glória tem lugar no fim do VI, enquanto o mais pungente desabafo do poeta sobre sua condição sacrificada e, no limite, suicidada, localiza-se no fim do VII. É preciso considerar ambas tendo em vista a condição de "parte excluída" que assola Baco e o poeta, sujeitos identificados em muitos aspectos ao longo do poema, "Porque também cos grandes e possantes", diz o filho de Sêmele, "Mostra a Fortuna injusta seus poderes." (VI, 15, 3-4) - entendo que grande e possante é o poeta pelo canto, e a divindade, por razões óbvias.

Luiza refere-se, no fragmento citado, ao licor de Lieu. O nome que aí identifica Baco significa, segundo Hennio Morgan Birchal, "o que liberta (dos cuidados). Refere-se aos efeitos do vinho" (BIRCHAL, 2005, p. 174). Cito a estância que lança mão desse epíteto no Canto VI, anterior à que tem o Tioneu como locutor e Netuno como alocutário; o visitante já não se detém nas maravilhas do fundo do mar, e encaminha-se para onde está o filho de Saturno:

Pouca tardança faz Lieu irado

$\mathrm{Na}$ vista destas cousas, mas entrando

Nos paços de Neptuno, que, avisado

Da vinda sua, o estava já aguardando,

Às portas o recebe, acompanhado

Das Ninfas, que se estão maravilhando

De ver que, cometendo tal caminho,

Entre no reino da água o Rei do vinho. (VI, 14)

"Lieu” no primeiro verso, "vinho" no último, na cena que terá a água como elemento, e é líquido o produto que vem de Baco. Agora sim esclareço comentário deixado no ar há muitas páginas: chama-me a aten- 
ção a rima em -inho na segunda estância do Canto VI porque ela se repete na 14. Na 2, a cena é contente, de festa, e "caminho" rima com "vizinho"; na 14, é cena de desabafo, e só então aparece a palavra "vinho". Por que digo isso? Porque o licor de Lieu, no Canto mais aquático d'Os Lusíadas, já que o único em que parte importante da ação ocorre no fundo, e não na superfície, do mar, aparece apenas como identificador do deus que o deu ao mundo. Luiza Nóbrega vai além disso; ela afirma que "água e vinho são termos duma imagem geminada". Além disso, "a água desejada, convertida em roxo sangue, denuncia seu caráter de sumo dionisíaco" (NÓBREGA, 2013, p. 546). Luiza refere-se a dois sintagmas do Canto I, encontrados na cena em que Baco alicia um mouro a fim de armar uma cilada contra os portugueses, que são salvos, pela primeira vez, por Vênus.

Não obstante, neste texto que parte de manjares e não quer esquecer os líquidos regalos, fica impossível ignorar que o vinho, no começo do VI, falta aos banquetes melindanos e, mais adiante, também aos ingleses. Por falar neles, concluo, enfim, o que noto como analógico no relato dos Doze de Inglaterra. Convencido por Baco no consílio, Netuno ordena a destruição da frota portuguesa pelos ventos. Vênus, mais uma vez, salva sua gente amada ao reunir as ninfas e fazê-las convencer Bóreas, Noto, etc., da insana violência do que estavam praticando, com um feminino discurso ligado a amor e delicadeza. Aqui a analogia: se Veloso, masculino e militar, afemina-se quando destaca os amores e os prazeres da estória que conta, ele é análogo a uma Vênus que celebra, poucas estâncias depois, uma força feminina ao conseguir, com as Ninfas, calar os ventos sem força bruta. $\mathrm{O}$ que acontece nos dois casos, na trama exposta pelo soldado e na engendrada pela deusa, também é mutuamente analogizável. Tudo isso relativiza a dicção masculina, contra a feminização e os "manjares novos e esquisitos", que encerra o Canto VI, e também o discurso católico e antimundano do começo de VII.

Após o Canto VI, a ocorrência seguinte de vinho se dá perto do fim do VII, quando Paulo da Gama recebe na embarcação o Catual indiano:

Pelo que vê pergunta; mas o Gama Lhe pedia primeiro que se assente E que aquele deleite que tanto ama A seita Epicureia experimente.

Dos espumantes vasos se derrama O licor que Noé mostrara à gente;

Mas comer o Gentio não pretende,

Que a seita que seguia lho defende. (VII, 75)

Como há muitos acepipes ocidentais a ele defesos, não come o visitante, não se configura, logo, o banquete. O gozo moderado se desfruta em meio a muitos pormenores, desde a aparição de Baco numa imagem do Palácio indiano, estrofes antes, até a aparição de seu filho Luso, pai mítico e fornecedor do nome dos portugueses e do poema, na primeira das bandei- 
ras que Paulo mostrará ao mouro. Mas é um vinho deveras comedido, tanto que sua presença é ligada a Noé, personagem bíblico, ainda que do Velho Testamento, e a Epicuro, cultor do prazer mas não do excesso. Já as duas ocorrências seguintes são muito significativas, e idênticas: "vinhos odoríficos". A primeira é dita por Vênus, aquando de seu diálogo com Cupido com vistas à elaboração da Ilha do Amor:

Ali, com mil refrescos e manjares,

Com vinhos odoríferos e rosas,

Em cristalinos paços singulares

Fermosos leitos, e elas mais fermosas;

Enfim, com mil deleites não vulgares,

Os esperem as Ninfas amorosas,

De amor feridas, pera the entregarem

Quanto delas os olhos cobiçarem.

Quero que haja no reino Netunino,

Onde eu nasci, progênie forte e bela,

E tome exemplo o mundo vil, malino,

Que contra tua potência se rebela,

Por que entendam que muro adamantino,

Nem triste hypocresia val contra ela:

Mal haverá na terra quem se guarde,

Se teu fogo imortal nas águas arde. (IX, 41, 42)

Baco protagoniza a ação central do Canto VI, o conjunto que envolve seu discurso e o resultado dele. Não penso que foi em vão a tentativa dionisíaca junto aos deuses do mar, por mais de uma razão. Em primeiro lugar, finalmente Baco encontrou ouvintes atentos a sua amargura, capazes de vê-la como justa, o que fica provado pela ação mandada por Netuno e aceita de bom grado por todos, exceto por Proteu, que quase diz o que só ele sabe, pois prevê o futuro; portanto, mesmo quem discorda o faz por motivos nada ideológicos. Além disso, Baco maravilha as ninfas ao cometer "tal caminho", e uma circunstância, ainda que longinquamente, remissora às bacantes em nada pode ser desagradável ao "Rei do vinho".

Recitei o último sintagma a fim de salientar que é nele a única ocorrência de vinho, expresso por esse vocábulo ou por sinônimo, no Canto VI. Não recuso a leitura de Luiza Nóbrega desse pormenor, vendo água e vinho geminadamente, ainda mais porque licor, em vários momentos do poema, ora aponta para água, ora para vinho, o que insinua identificação. Por outro lado, tampouco posso deixar de notar a ausência de celebração vínica no Canto em que Baco mostra, com muita sensatez, seu triste desespero, numa tentativa que não reputo vã, mas que foi incapaz, no fim das contas, de mudar o destino da viagem dos portugueses. Nesse sentido, posso supor que foi necessário haver duas intervenções venusianas para 
que a alegria do vinho fosse recuperada, e algumas alianças, enfim, feitas. Uma delas, claro, é entre os portugueses e seu antepassado, pois o vinho será elemento central na celebração da Ilha do Amor. Se não, vejamos a outra aparição de "vinhos odoríficos", já após o bacanal entre navegadores e ninfas:

Ali, em cadeiras ricas, cristalinas,

Se assentam dous e dous, amante e dama;

Noutras, à cabeceira, d'ouro finas,

Está co a bela Deusa o claro Gama.

De iguarias suaves e divinas,

A quem não chega a Egípcia antiga fama,

Se acumulam os pratos de fulvo ouro,

Trazidos lá do Atlântico tesouro.

Os vinhos odoríferos, que acima

Estão não só do Itálico Falerno

Mas da Ambrósia, que Jove tanto estima

Com todo o ajuntamento sempiterno,

Nos vasos, onde em vão trabalha a lima,

Crespas escumas erguem, que no interno

Coração movem súbita alegria,

Saltando co a mistura da água fria. $(\mathrm{X}, 3,4)$

A palavra vinho, no singular ou no plural, só é grafada, no poema inteiro, nas três situações elencadas: a do "Rei do vinho" dentro do mar e as dos "vinhos odoríferos"; a indicação do precioso licor, contudo, se dá muitas outras vezes. No começo do Canto X, não se lê a palavra banquete, mas o que acontece é um banquete. Essas estrofes indicam que o planejamento de Vênus foi plenamente cumprido, propiciando acordo contente, com base no amor (especialidade da deusa, é óbvio), entre humanos e ninfas. Como se trata de um bacanal amoroso, também ficam aliançados, com vinho a despertar, transbordando de seus "vasos", "súbita alegria", Vênus e Baco - Lieu, nessa cena de libertação vinária e erótica, é memória mais que presente. E, enfim, a cena aliança o masculino dos navegadores ao feminino das ninfas, relembrando a combinação fecunda entre braço e afeto que coroa o relato dos Doze de Inglaterra.

Não se lê banquete, mas se lê "manjares", primeiro em IX, 41, depois em X, 2, "Mesas d'altos manjares excelentes" (X, 2, 6). O resultado das citadas alianças deverá ser o que Vênus chama de "progênie forte e bela", cuja ação será em nome do amor e contra qualquer "hypocresia" que se oponha ao mais valoroso índice de humanidade do humano. Estão aliançados também o presente e o futuro, o mundo e a eternidade, estando nesse ponto uma das mais ousadas superações camonianas de uma dicotomia, no caso a que opõe o amor humano a um valor mais alto e eventualmente sem 
corpo. A progênie é utópica quimera da deusa cípria, que entende muito bem que não há a menor vulgaridade numa prática que alia sexualidade e sentimento amoroso. Ao contrário do que diz o narrador no momento, primeiro sectariamente masculino, depois católico, que vai do final do Canto VI ao começo do VII, é possível haver “deleites não vulgares", e deles fazem parte, evidentemente, os banquetes, o vinho, os manjares.

Duas construções já citadas neste ensaio sabem-me deliciosas. Uma é dita por Vênus, enquanto instrui Cupido sobre a Ilha do Amor; lá, as ninfas estarão para "entregarem" aos seus amantes "Quanto delas os olhos cobiçarem”. A outra está no clímax da narrativa dos Doze de Inglaterra: as Damas "querem dar aos seus libertadores/ Banquetes mil". Vênus, ao insuflar uma entrega à cobiça, lembra-me o famoso e bastante atual uso de entregar-se, que sugere ser debalde, em certos contextos, resistir, não raro em situações de ordem erótico-amorosa. O indivíduo entrega a si próprio, dando-se ao outro e a seu desejo - o último possessivo é propositadamente ambíguo.

A associação que Os Lusíadas faz, mais de uma vez, entre manjar e amor, ou entre o corpo de alimentos apetitosos e corpos mais apetitosos ainda, faz-me pensar, no caso luso-bretão, num uso brasileiro e português do verbo comer, e num uso mais brasileiro que português do verbo dar. Se os "libertadores" comem os banquetes oferecidos pelas Damas num sentido eroticamente interessado, eles talvez estejam comendo as mesmas Damas. Já elas, se "querem dar", como verbo intransitivo, "aos seus libertadores", estão escolhendo parceiros a que poderão, por sua vez, comer. Mudam-se os tempos, não se mudam tanto as vontades, pois ainda hoje, a humanos com boca e resto do corpo que somos, pouca coisa interessa mais que comer, em ambos os sentidos, e costumamos preferir, dada a alguma sabedoria que temos, os banquetes, os manjares desusados. Como também sabemos falar, outra delícia, para encerrar o texto: diz-me o citado Houaiss que o francês manger, de onde vem manjar, significava também, por volta do fim do século XVII, "pronunciar corretamente as palavras". A boca é realmente muito importante para os seres que somos.

\section{REFERÊNCIAS BIBLIOGRÁFICAS}

BIRCHAL, Hennio Morgan. Os Lusíadas de Luís de Camões. Edição antológica, comentada e comparada com Ilíada, Odisseia e Eneida. São Paulo: Landy, 2005.

CAMÕES, Luis de. Os Lusíadas. Edição organizada por Emanuel Paulo Ramos. Porto: Porto editora, 1978.

Dicionário Eletrônico Houaiss da língua portuguesa. Manaus: Sonopress Rimo da Amazônia Indústria e Comércio Fonográfica; Rio de Janeiro: Objetiva, 2001. 
NÓBREGA, Luiza. No reino da água o rei do vinho - submersão dionisíaca e transfiguração trágico-lírica d' Os Lusíadas. Natal: Editora da UFRN, 2013.

SCHIFF, Stacy. Cleópatra - uma biografia. Tradução de José Rubens Siqueira. Rio de Janeiro: Zahar, 2011.

SILVA, Vítor Aguiar e. Jorge de Sena e Camões - trinta anos de amor e melancolia. Coimbra: Angelus Novus, 2009.

Recebido para publicação em 20/11/2013

Aprovado em 15/02/2014 